\title{
Otimização da performance da linha de produção mediante a implantação da Manutenção Produtiva Total
}

\section{Optimization of production line performance through the implementation of Total Productive Maintenance}

\author{
Edson Detregiachi Filho ${ }^{1}$ \\ Vânia Érica Herrera ${ }^{2}$ \\ Cristian Junior Alves de Souza ${ }^{3}$ \\ Marlene de Fátima Campos $\operatorname{Souza}^{4}$
}

\begin{abstract}
RESUMO: Análises realizadas em unidades produtivas, permitem verificar a ocorrência de quebra de equipamentos interrompendo a linha de produção, afetando diretamente os indicadores de performance, aumentando os custos e reduzindo a produtividade. Com a implantação e utilização da metodologia da Manutenção Produtiva Total, é possível a otimização do processo produtivo. Essa metodologia compreende um abrangente conjunto de atividades de manutenção que visam melhorar o desempenho e a produtividade dos equipamentos de uma fábrica. $\mathrm{O}$ objetivo desse trabalho é analisar a performance de uma linha de produção de alimentos, antes da implantação da Manutenção Produtiva Total e comparar esses dados com aqueles obtidos após sua implantação, para verificar se houve melhorias. A metodologia utilizada será o da pesquisa qualitativa combinada com a quantitativa, utilizando a estratégia do estudo de caso em uma indústria alimentícia localizada no interior do estado de São Paulo. O desenvolvimento desse trabalho permitiu constatar que, com a implantação da Manutenção Produtiva Total houve um aumento em todos os índices de performance da linha de produção analisada. Esse trabalho é relevante pois, além de orientar a empresa foco do estudo de caso, servirá de orientação para outras empresas que buscam melhorar a produtividade e a qualidade dos processos produtivos.
\end{abstract}

Palavras-chave: Manutenção Produtiva Total. Produtividade. Performance. Qualidade. Disponibilidade de máquinas.

\footnotetext{
${ }^{1}$ Doutor em Educação (UNESP), docente e pesquisador do Curso de Engenharia de Produção do Centro Universitário Eurípides de Marília - UNIVEM, Marília-SP. Docente do Curso de Tecnologia em Mecatrônica Industrial da Faculdade de Tecnologia de Garça-SP, Brasil, do CEETEPS. engedson2009@gmail.com

${ }^{2}$ Doutoranda (PUC-SP), Mestre em Engenharia de Produção (UFSCar), Coordenadora dos cursos de Engenharia de Produção e Administração de Empresas do Centro Universitário Eurípides de Marília - UNIVEM, Marília - SP, Brasil.vania@univem.edu.br

${ }^{3}$ Engenheiro de Produção, egresso do Curso de Engenharia de Produção do Centro Universitário Eurípides de Marília - UNIVEM, Marília-SP, Brasil. cjas87@hotmail.com

${ }^{4}$ Doutora em Ciências Sociais (PUC-SP), Coordenadora do Curso de Ciências Contábeis e Pró-Reitora Administrativa do Centro Universitário Eurípides de Marília-UNIVEM, Marília, Brasil. marlene@univem.edu.br
} 
ABSTRACT: Before treated as a factor to additional costs and with little visibility for companies, maintenance was gradually being improved and gaining its importance, today it is considered a strategic role in Industrial environment. The Total Productive Maintenance with its set of maintenance activities aimed to improve performance and equipment 's productivity has won many supporters. This study aims to propose the use of the TPM methodology to eliminate losses by reducing equipment breakdowns making reliable and as a result increasing its performance. Seek to improve the business structure and equipment, developing people and making them more autonomous, improving methods of productions and services, seeking the continuous elimination of loses and wastes to achieve the desired productivity. This study found that the deployment of TPM tool provided the company a gain in productivity mainly due to reduced breakdown and equipment failure, as it is well known that for organizations survive the current market, costs reductions are essential and TPM helps to make it happen.

Keywords: Total productive maintenance. Productivity. Performance. Quality. Availability of machines.

\section{INTRODUÇÃO}

No início dos anos 70, nascia no Japão a Manutenção Produtiva Total com o objetivo principal, segundo Yamashina (2000), de aumentar a rentabilidade dos negócios mediante a diminuição de falhas por quebras de equipamentos, além de melhorar a qualidade final dos produtos.

A Manutenção Produtiva Total, tradução para o português de Total Productive Maintenance (TPM), compreende um abrangente conjunto de atividades de manutenção que visam melhorar a performance e a produtividade dos equipamentos de uma fábrica. A palavra Total significa que todos no ambiente de trabalho estão envolvidos na cultura e nas atividades do TPM, desde a gerência, até os operários. A implantação de um programa TPM necessita do envolvimento de todos, não somente de alguns grupos de pessoas. Ela depende principalmente da aceitação da direção da fábrica que, por sua vez, deve difundir seus conceitos e dar suporte para que o programa evolua positivamente.

Portanto, antes tratada como fator de custos adicionais e com pouca visibilidade para as empresas, a manutenção aos poucos foi sendo aperfeiçoada e ganhando a sua devida importância, sendo atualmente considerada uma função estratégica no ambiente industrial, com um agente de otimização da produção e, consequentemente, aumentando a produtividade e gerando lucros.

Análises realizadas em unidades produtivas, permitem verificar a ocorrência de quebra de equipamentos, interrompendo a linha de produção, afetando diretamente os indicadores de performance, aumentando os custos e reduzindo a produtividade. Com a implantação e 
utilização da ferramenta TPM é possível a otimização do processo produtivo. Para medir as melhorias implementadas pela ferramenta TPM, um dos métodos empregados é o indicador OEE (Overall Equipament Effectivences) que verifica a eficiência geral do equipamento ou a eficiência global de máquinas. $\mathrm{O}$ emprego do OEE permite à empresa verificar as condições reais da utilização de seus ativos. As análises das condições acontecem a partir da identificação das perdas existentes em ambiente fabril, envolvendo índices de disponibilidade de equipamentos, performance e qualidade (SANTOS; SANTOS, 2007).

O objetivo desse trabalho é analisar a performance de uma linha de produção de alimentos, antes da implantação da Manutenção produtiva Total e comparar esses dados com aqueles obtidos após sua implantação, para verificar se houve melhorias. Como objetivos específicos será analisado o índice de disponibilidade de máquinas, verificado as perdas por defeitos de qualidade, será efetuado cálculo do indicador OEE, elaborado análise e comparação dos dados obtidos antes e depois da implementação da TPM.

A metodologia utilizada será o da pesquisa qualitativa combinada com a quantitativa, utilizando a estratégia do estudo de caso em uma indústria alimentícia localizada no interior do estado de São Paulo. O estudo de caso tem como particularidade um estudo detalhado de um ou de vários objetos, permitindo adquirir um grande conhecimento sobre o assunto. $\mathrm{O}$ estudo de caso é adequado quando buscamos compreender, explorar ou descrever fatos e contextos complicados, nos quais estão simultaneamente envolvidos múltiplos fatores, serve como estímulo a novas descobertas e permite ao pesquisador verificar os diversos ângulos de um problema. (YIN, 2002).

A abordagem da pesquisa será a combinação de quantitativa e qualitativa, que Mello e Turrioni (2012) definem que nessa abordagem o pesquisador pode combinar aspectos das pesquisas qualitativas e quantitativas em todos ou em algumas das etapas do processo de pesquisa.

Dessa forma, a pesquisa combinada, agregando as características qualitativa e quantitativa, apresenta-se como a forma de abordagem da presente pesquisa, que levantou elementos observados na linha de produção como qualidade do trabalho, capacidade produtiva e funcional e o impacto do funcionário capacitado para a preservação do equipamento.

Esse trabalho é relevante pois, além de orientar a empresa foco do estudo de caso quanto à eficiência e eficácia da ação implementada, servirá de orientação para outras empresas que buscam melhorar a produtividade e a qualidade dos processos produtivos. 


\section{REFERENCIAL TEÓRICO}

Segundo Yoshicazem (2002), a Manutenção Produtiva Total ou TPM surgiu no Japão na década de 1970, por meio do aprimoramento das técnicas de Manutenção Preventiva, Manutenção do Sistema de Produção, Manutenção Preventiva e Engenharia de Confiabilidade, visando à falha zero e quebra zero dos equipamentos juntamente com o defeito zero nos produtos e perda zero no processo.

O TPM tem como objetivo identificar e eliminar as perdas dos processos, maximizando a utilização dos ativos e garantindo a geração de produtos de alta qualidade a custos competitivos, mas para que isso aconteça, existe a necessidade de se reeducar as pessoas para a prevenção e a melhoria contínua, aumentando a confiabilidade do equipamento e a capacidade dos processos, sem investimentos adicionais. (YOSHICAZEM, 2002, p. 58).

Segundo Tenorio (2000), foi em meio à busca constante do aumento da qualidade pelos japoneses que se desenvolveu a Manutenção Produtiva Total (TPM), que com o passar dos anos vem evoluindo cada vez mais de uma metodologia simples de manutenção para um sistema completo de gestão do sistema produtivo. Com o objetivo de tentar antever a ocorrência da falha por monitoramento e medições, surge a Manutenção Preditiva cuja intervenção no equipamento passa a ser baseada na sua condição e não mais no tempo de operação, o que marca o surgimento da era da manutenção baseada na condição do equipamento e passando a fazer parte significativa do TPM, pois utiliza técnicas modernas de supervisão para diagnosticar o estado do equipamento durante a operação.

A figura 1 ilustra de forma bastante pertinente toda essa evolução, e apresenta de forma sintética as diversas fases do processo de manutenção e sua evolução para a Manutenção Produtiva Total. 


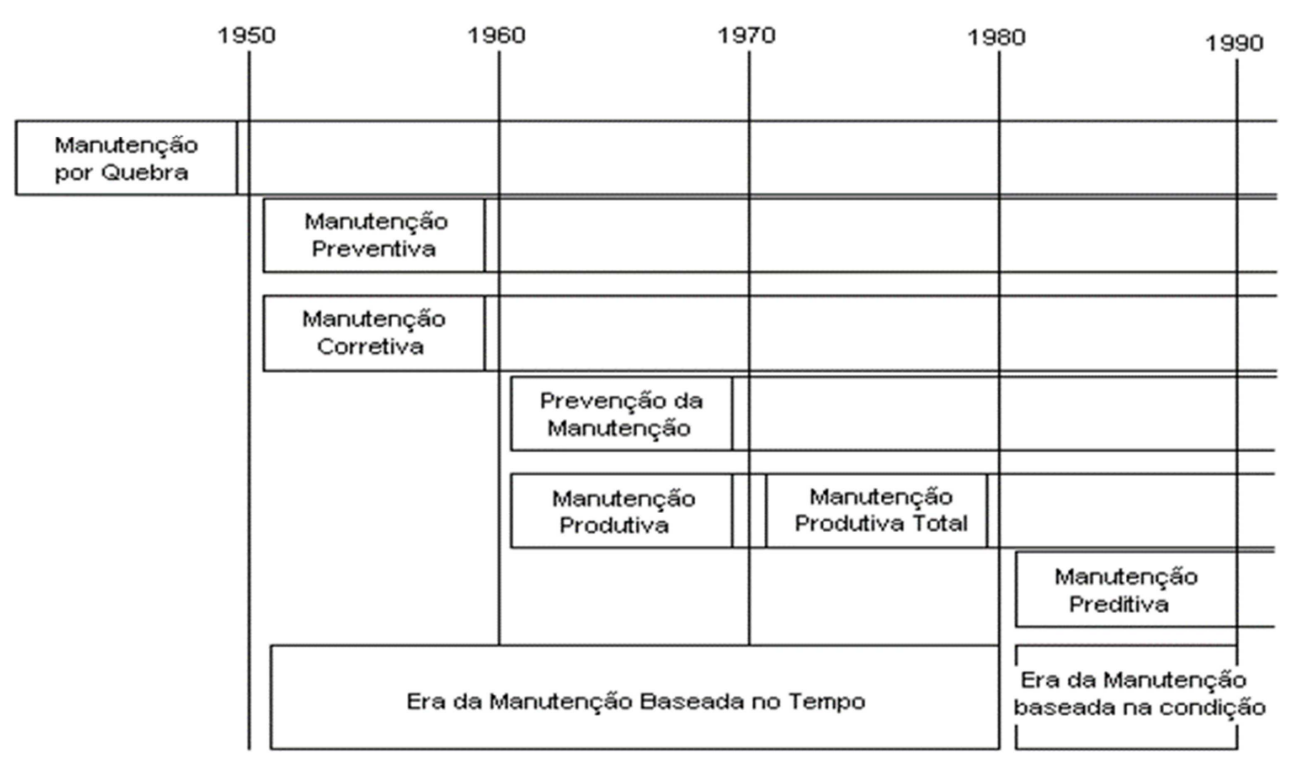

Figura 1 - Evolução do Processo de Manutenção

Fonte: Pires (2005, p. 39) apud Tenorio (2000).

De acordo com Nakajima (1989), um alto funcionário do Japan Institute of Plant Maintenance "JIPM" propôs um significado para cada letra do termo TPM:

T - Total: Total nos sentidos de eficiência global, ciclo total de vida útil do sistema de produção;

$\mathbf{P}$ - Produtiva: A busca do sistema de produção até o limite máximo da eficiência, atingindo "zero acidentes, zero defeitos e zero quebras e falhas", ou seja, a eliminação dos desperdícios e perdas;

M - Manutenção: Manutenção no sentido amplo, que tem como objetivo o ciclo total de vida útil do sistema de produção.

Segundo Nakajima (1989), o TPM pode aperfeiçoar o rendimento global das instalações por meio de uma organização fundamentada no respeito à criatividade humana e com a participação geral de todos os empregados da empresa. Para Suzuki (1994), houve razões principais pelas quais a TPM se disseminou tão rapidamente na indústria japonesa e agora o mesmo está acontecendo em todo o mundo, pois garante resultados eficientes, altera visivelmente os lugares de trabalho e eleva o nível de conhecimento e capacidade dos trabalhadores de produção e manutenção.

Tenorio (2000) também aponta que um dos princípios básicos da TPM, é a eliminação total das perdas por toda a empresa. Esse autor salienta ainda que, além da melhoria dos resultados da empresa, obtidos por meio da eliminação das perdas e redução dos custos, a 
TPM visa melhorar o ambiente de trabalho, transformando as instalações, normalmente impregnadas por sujeira, em ambientes agradáveis e seguros.

Em relação ao desenvolvimento do nível de conhecimento, Tenorio (2000) cita que isto acontece à medida que as atividades de TPM vão sendo cumpridas, motivando empregados, aumentando a integração no trabalho e elevando o número de sugestões espontâneas de melhorias.

Segundo Yamashina (2000), o TPM ajuda os operadores a entender seu equipamento e ampliar a gama de tarefas de manutenção que podem praticar. Dá-lhes oportunidade de fazer novas descobertas, adquirir conhecimentos e desfrutar de novas experiências. Reforça a motivação, gera interesse e preocupação pelo equipamento e alimenta o desejo de manter o mesmo em ótimas condições.

De acordo com Fernandes (2005), o TPM contém um conjunto de atividades de manutenção que buscam aprimorar a performance e a produtividade dos equipamentos de uma organização, visando: criar uma cultura corporativa que persiga invariavelmente o avanço da eficiência de todo o sistema produtivo; construir um sistema para prevenir qualquer tipo de perda para atingir o zero acidente, zero defeito e zero falha em todo o sistema de produção; envolver todos os departamentos; buscar o envolvimento de todos, desde a direção até os colaboradores da fábrica; atingir perda zero através das atividades de pequenos grupos. Ainda, segundo Fernandes (2005), um aspecto importante a ser considerado é que todos esses conceitos de TPM não são estáveis e sofrem alterações constantemente à medida que o método evolui. Além disso, desenvolve conhecimentos capazes de reeducar as pessoas para ações de prevenção e de melhoria contínua, garantindo o aumento da confiabilidade dos equipamentos e da capabilidade dos processos, sem investimentos adicionais.

Já, para Kardec e Nascif (2009), a estrutura do TPM está conceitualmente apoiada em oito pilares, sendo que a aplicação de todos esses conceitos levará a empresa a um resultado de excelência. Esses pilares possuem objetivos próprios, conforme demonstrado na figura 2. 


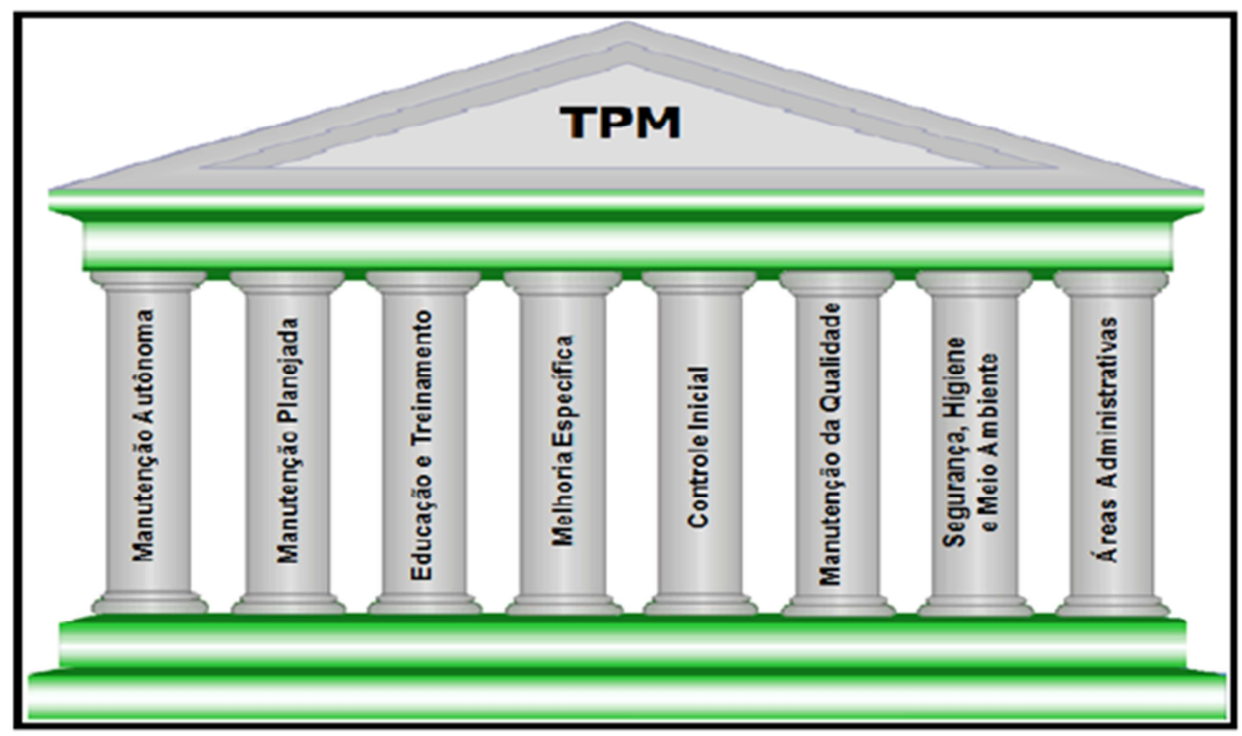

Figura 2 - Pilares do TPM

Fonte: adaptado de Kardec e Nascif (2009, p.199)

O pilar Manutenção Autônoma é responsável pelo autogerenciamento e controle do equipamento, a fim de detectar e lidar prontamente com as anormalidades encontradas, de forma a conservar as condições ideais de funcionamento. (KARDEC E NASCIF, 2009)

De acordo com Xenos (2004), a manutenção autônoma é basicamente uma estratégia para envolver os operadores nas atividades de manutenção diária como limpeza, lubrificação e inspeção, é um passo adiante no que diz respeito ao envolvimento das áreas de manutenção e produção.

Existem algumas etapas para implantar a manutenção autônoma. A primeira delas é a de limpeza e inspeção, que tem como objetivo eliminar toda a sujeira e o acúmulo de resíduos limpando completamente o equipamento, garantindo assim que a deterioração ocasionada pela poeira e por resíduos seja extinta. Pontos de difícil acesso devem também ser identificados e eliminados. A consolidação desta etapa é a familiarização do operador com o equipamento, tornando-o hábil a identificar anomalias. Quando inicia as atividades de TPM em um equipamento, os operadores encontrarão diversas anomalias que devem ser identificadas. E uma forma de tornar o problema visível é a utilização das etiquetas, que são divididas em duas classes e identificadas por cores. As etiquetas vermelhas representam anomalias encontradas pelo operador e que ele não tem condições de resolver e etiquetas azuis, que representam anomalias encontradas pelo operador e por ele resolvidas. (XENOS, 2004).

A segunda etapa é a de identificar as causas das anomalias e estabelecer contramedidas. Após identificar e eliminar as causas das anomalias, criar contramedidas que 
impeçam sua reincidência. Verificar as fontes de sujeira, procurando aprimorar o acesso às áreas difíceis, facilitando e tornando mais rápida a limpeza. É fundamental a participação de toda equipe e acompanhar a eficácia das ações estabelecidas e, se necessário, criar um plano de ação para reparar anomalias pendentes. (XENOS, 2004).

A terceira etapa é da padronização das atividades, que tem por objetivo o controle das atividades básicas que impeçam que o equipamento deteriore e também, nessa etapa, deverá ser analisado três requisitos básicos, quais sejam: limpeza/inspeção, lubrificação e reaperto. Há necessidade de estabelecer metas de tempo para os operadores realizarem as atividades de manutenção autônoma, elaborar procedimentos para as rotinas de inspeção, limpeza e lubrificação para evitar a degradação do equipamento. (XENOS, 2004).

Xenos (2004) aponta ainda, a quarta etapa que é a inspeção geral. Nessa etapa, inspecionam-se as partes principais do equipamento com objetivo de detectar anomalias e falhas ocultas. Para atuar nessa etapa é preciso adquirir conhecimentos e capacitação para assim reconhecer as condições ótimas de funcionamento do equipamento.

Ainda em relação ao quesito inspeção, Xenos (2004) aponta a quinta etapa que consiste na inspeção dos equipamentos. Nessa etapa o operador é habilitado para detectar anomalias e estabelecer ações corretivas adequadas, aperfeiçoar os padrões revisando os padrões provisórios elaborados anteriormente.

Como sexta etapa, a padronização do local de trabalho que visa aumentar a abrangência da manutenção autônoma por meio do gerenciamento do local de trabalho, melhorar a organização, a ordem e assim aumentar a eficiência do trabalho desenvolvido. As principais atividades dessa etapa são a revisão dos itens a serem controlados no local de trabalho e a revisão do controle feito visualmente. A realização e a ordem em termos gerais, tanto no aspecto físico como no administrativo são pontos importantes dessa etapa. (XENOS, 2004).

Finalizando a sequência de etapas, Xenos (2004) aponta a sétima, que é a efetivação do controle autônomo. Nessa última etapa o operador estará apto para diagnosticar e reparar o equipamento, auxiliar a manutenção na coleta de vários tipos de dados, sendo capaz de analisar e propor melhorias visando o aumento da confiabilidade, mantenabilidade e implementar melhorias para estender a vida útil do equipamento.

Segundo Kardec e Nascif (2009), manutenção planejada significa ter realmente um planejamento e controle da manutenção, visa à conscientização das perdas oriundas das falhas 
de equipamentos e as mudanças de mentalidade da produção e manutenção, diminuir as falhas e defeitos com o mínimo custo, mantendo condições ótimas de processos e equipamentos, através de atividades de melhoria continua e gerenciamento da manutenção.

Já, pilar educação e treinamento, tem como objetivo ampliação da capacidade técnica, gerencial e comportamental. Busca desenvolver e transmitir novos conhecimentos e habilidades para o pessoal da manutenção e da produção. De acordo com a filosofia TPM, habilidade é o poder de agir de forma correta e automática, com base em conhecimentos adquiridos sobre todos os fenômenos e utilizá-los durante um grande período. (KARDEC E NASCIF, 2009)

Ainda, de acordo com Kardec e Nascif (2009), a melhoria específica consiste em focar a melhoria global do negócio reduzindo os problemas para aumentar o desempenho, tendo como objetivo a eliminação das perdas existentes no processo produtivo, obtendo a eficiência máxima dos equipamentos. Esses autores apontam que o pilar controle inicial visa estabelecer um sistema de gerenciamento da fase inicial para novos projetos, eliminar as falhas no início e implantar sistemas de monitoramento.

Ainda recorrendo à Kardec e Nascif (2009), a manutenção da qualidade visa garantir zero defeito de qualidade, estabelecendo um programa para zero defeito mantendo condições ideais dos equipamentos, materiais, métodos e pessoas. Em relação ao pilar TPM Office ou Administrativo, esses autores (2009) afirmam que têm como objetivo estabelecer um programa de TPM na área administrativa buscando aumentar a eficiência, reduzindo as perdas nos processos administrativos, acabar com os retrabalhos e atividades que não agregam valor. Além de aprimorar o trabalho administrativo, eliminando-se desperdício e perdas geradas pelo trabalho de escritório, é necessário que todas as atividades organizacionais sejam eficientes.

Segundo Kardec e Nascif (2009) o principal objetivo do pilar segurança, saúde e meio ambiente é garantir "o zero acidentes", além de proporcionar um sistema que garanta a preservação da saúde e bem estar dos funcionários e do meio ambiente, e estabelecendo um sistema para controlar a saúde segurança e meio ambiente no ambiente fabril.

Para medir as melhorias implementadas pela ferramenta TPM, um dos métodos empregados é o indicador OEE. O emprego do indicador OEE permite às empresas verificar as condições reais da utilização de seus ativos. As análises das condições acontecem a partir da identificação das perdas existentes em ambiente fabril, envolvendo índices de disponibilidade de equipamentos, performance e qualidade (SANTOS; SANTOS, 2007). 
Segundo Hansen (2006), o indicador OEE é uma ferramenta que mostra o quanto do equipamento ou da fábrica estamos deixando de aproveitar, o uso deste indicador nos dá a dimensão do que estamos deixando de lado.

\section{Tempo total disponível}

\begin{tabular}{|l|l|}
\hline A & Tempo disponivel para produção \\
\hline B & Tempo real de produção \\
\hline
\end{tabular}

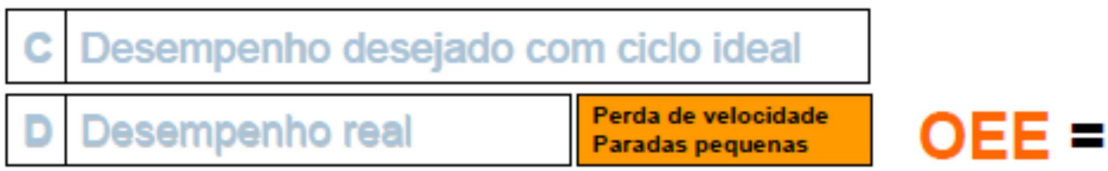

\begin{tabular}{|l|l|l|}
\hline E & Qtd produtos total \\
\hline \hline F & Qtd produtos OK $\begin{array}{l}\text { Sucata } \\
\text { Retrabalho }\end{array}$ \\
\hline
\end{tabular}

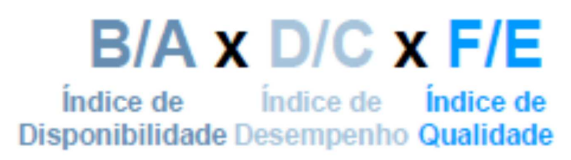

Figura 3 - Forma de Calcular o OEE

Fonte: SANTOS; SANTOS (2007, p.05)

Atualmente, o OEE é considerado um dos principais indicadores na medição do desempenho no ambiente fabril, pois pode ser usado para avaliar a produtividade e atuar para aumentar os lucros da empresa. (HANSEN, 2006). O OEE é representado por três termos que relacionam as seis grandes perdas como pode ser visto na figura 3.

\section{ESTUDO DE CASO}

O estudo de caso foi realizado em uma empresa do ramo alimentício localizada no interior do estado de São Paulo, sendo que a fábrica conta com 10 linhas de produção em atividade. O foco do estudo foi uma linha de fabricação de biscoitos recheados que corresponde a aproximadamente $17 \%$ da capacidade produtiva da unidade produtiva. Os processos utilizados nesta linha são: batimento da massa dos biscoitos, realizada em misturadores com a função de homogeneizar os ingredientes para formar massa uniforme; moldagem do biscoito; assamento do produto; resfriamento, que é uma das operações mais importantes na fabricação dos biscoitos (nessa etapa ocorre a equalização da umidade na base do produto final); recheamento (nessa operação o biscoito recebe o recheio e é formado o sanduíche onde é controlado o peso final do produto); acondicionamento do produto na embalagem. 
Inicialmente foi analisado o controle de paradas da linha de produção mantido pela empresa, que arquiva formulários contendo informações quanto ao tempo de parada das máquinas e as causas pelas quais ocorreram, sendo arquivado para consultas oportunas. Foi analisado um período de seis meses anteriores à implantação da TPM, considerando-se as horas programadas para produzir em cada mês e o quanto realmente produziu. E, a partir dos dados coletados, elaborou-se a tabela 1, relacionando-se as horas programadas e efetivamente trabalhadas da linha de produção.

Tabela 1 - Horas Disponíveis

\begin{tabular}{|c|c|c|c|}
\hline \multicolumn{4}{|c|}{ Horas disponiveis } \\
\hline & $\begin{array}{c}\text { Horas } \\
\text { Programadas }\end{array}$ & $\begin{array}{c}\text { Horas } \\
\text { Trabalhadas }\end{array}$ & $\begin{array}{c}\text { Horas } \\
\text { Paradas }\end{array}$ \\
\hline Mês 1 & 642 & 606 & 36 \\
\hline Mês 2 & 646 & 591 & 55 \\
\hline Mês 3 & 674 & 609 & 65 \\
\hline Mês 4 & 630 & 584 & 46 \\
\hline Mês 5 & 699 & 654 & 45 \\
\hline Mês 6 & 617 & 566 & 51 \\
\hline Total & 3908 & 3610 & 298 \\
\hline
\end{tabular}

Fonte: Os autores

Para efetuar o cálculo de disponibilidade do equipamento, utilizou-se o método apresentado na figura 4. O resultado do cálculo de disponibilidade resultou no valor de 92, $37461 \%$, que significa a possibilidade de melhoria de 7,625539\%, até o limite máximo de $100 \%$, pois no período avaliado houve 298 horas com a linha de produção parada, ociosa, sem produzir.

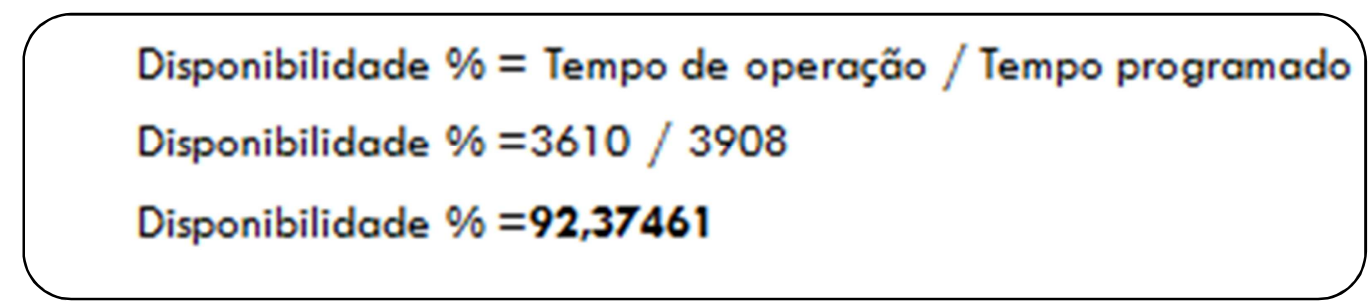

Figura 4 - Cálculo da disponibilidade de máquina Fonte: Os autores

Durante o período avaliado foi verificado junto aos formulários arquivados, as perdas da linha de produção, a relação entre o que foi produzido e as perdas por defeito de qualidade. Esses formulários são preenchidos diariamente e ,ao final do mês, é feito fechamento da linha de produção. A compilação dos dados obtidos nos formulários permitiu elaborar a tabela 2. 
Tabela 2 - Produção e Perdas Mensais

\begin{tabular}{|c|c|c|c|}
\hline & \multicolumn{4}{|c|}{ Produção x Perdas } \\
\hline & $\begin{array}{c}\text { Quantidade } \\
\text { Produzida (kg) }\end{array}$ & $\begin{array}{c}\text { Produto Bom } \\
\text { (Kg) }\end{array}$ & Perdas (kg) \\
\hline Mês 1 & 1497943,00 & 1453135,00 & 44808,00 \\
\hline Mês 2 & 1381690,00 & 1320475,00 & 61215,00 \\
\hline Mês 3 & 1509883,00 & 1441158,00 & 68725,00 \\
\hline Mês 4 & 1452761,00 & 1396120,00 & 56641,00 \\
\hline Mês 5 & 1583187,00 & 1518035,00 & 65152,00 \\
\hline Mês 6 & 1403121,00 & 1356396,00 & 46725,00 \\
\hline Total & 8828585,00 & 8485319,00 & 343266,00 \\
\hline
\end{tabular}

Fonte: Os autores

Os dados obtidos na tabela 2 permitiram efetuar o cálculo de desempenho da qualidade, conforme especificado na figura 5, considerando-se a quantidade de produto bom (produto em conformidade com a qualidade desejada) com o total produzido.

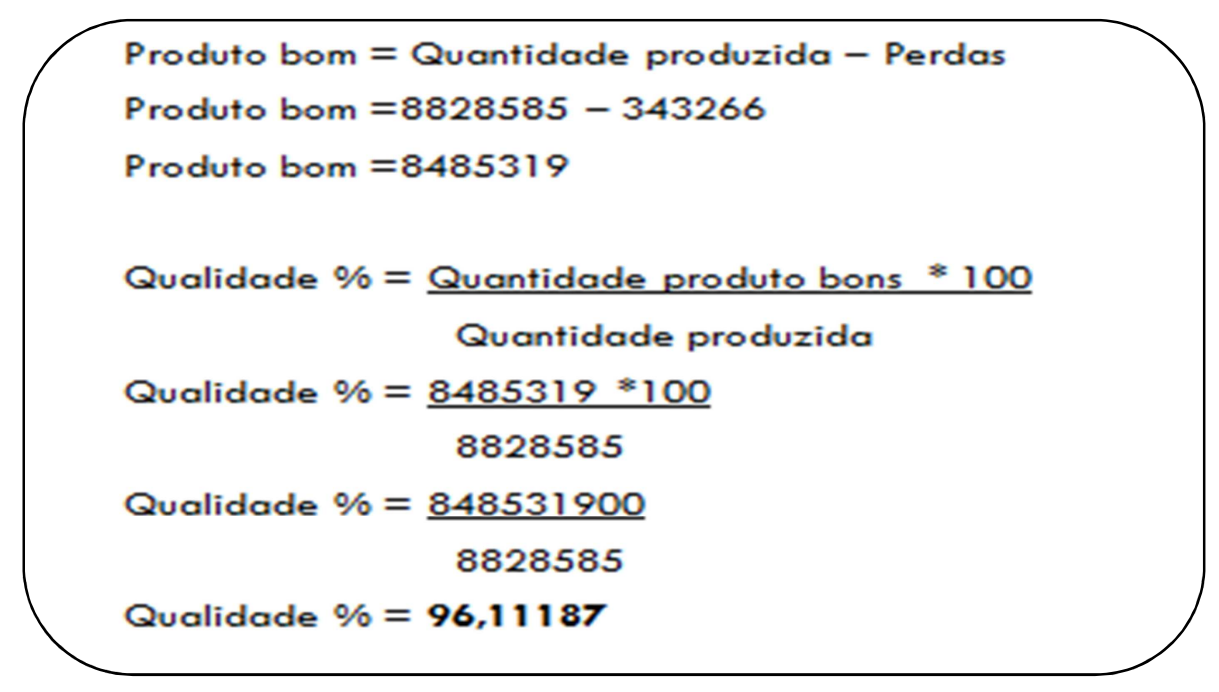

Figura 5 - Cálculo da Qualidade Fonte: Os autores

Para o cálculo de desempenho da linha de produção, conforme especificado na figura 6 , devese usar como taxa standard da linha o valor de $2531 \mathrm{~kg} / \mathrm{h}$, que é a quantidade que deve ser produzida por hora nesta linha. Este valor é determinado pelo corporativo da empresa no início do ano, levando em consideração o desempenho da linha no ano anterior. O cálculo de desempenho conduziu ao resultado de $96,6255 \%$ de desempenho. 


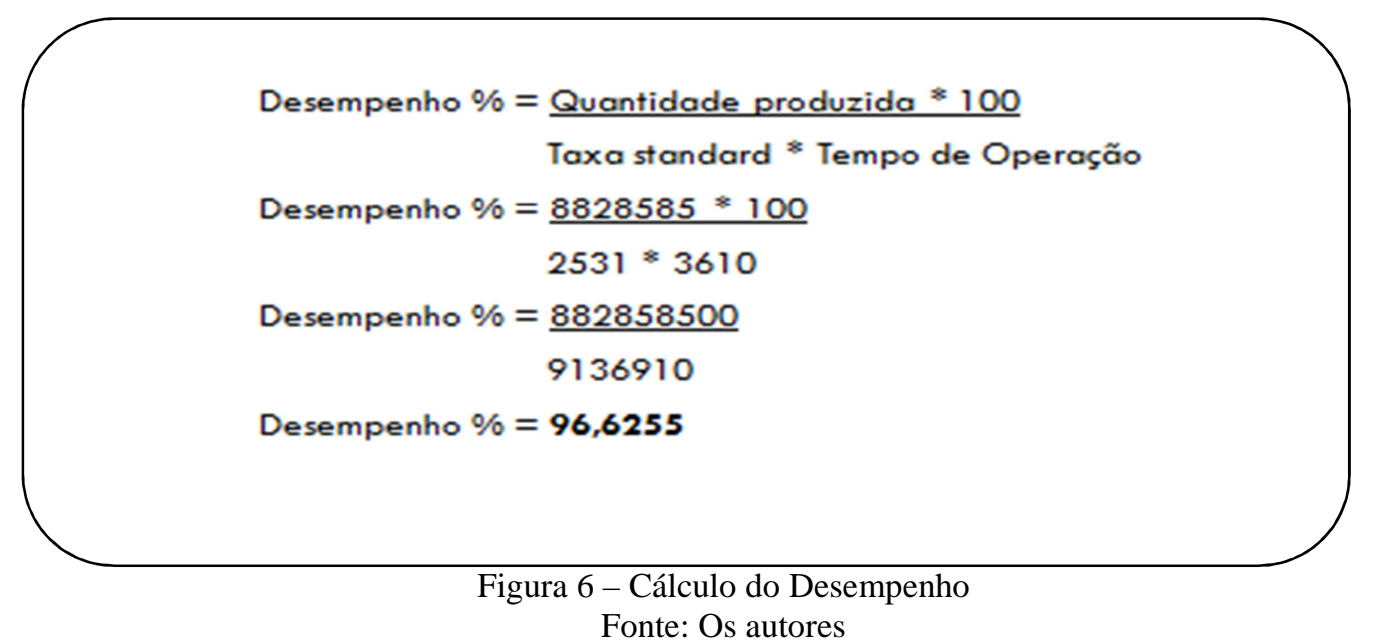

Fonte: Os autores

Multiplicando os valores dos três índices, conforme especificado na figura 7, disponibilidade de máquinas, desempenho da qualidade e desempenho da linha de produção, obter-se-á o índice OEE que é a eficiência global do equipamento na linha de produção.

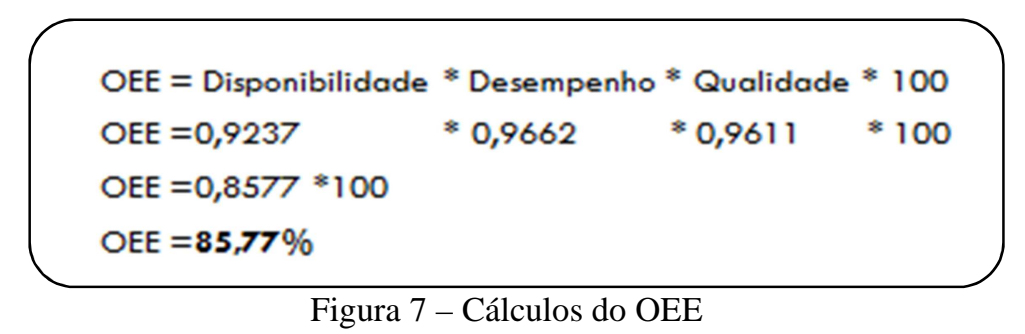

Fonte: Os autores

Portanto, a linha de produção analisada apresenta um OEE de 85,77 \%, revelando a oportunidade de melhorias. Posteriormente à implantação da TPM, será verificado se os avanços ocorreram e qual a relação entre os valores obtidos antes a após a ação de implementação da TPM.

\section{ANÁLISE DOS RESULTADOS}

Após a implantação da TPM, foi repetido o estudo efetuado antes de sua implementação, considerando igual período de seis meses de amostragem. Nessa segunda etapa da pesquisa foram igualmente verificadas, junto aos formulários arquivados, as perdas da linha de produção, a relação entre o que foi produzido e as perdas por defeito de qualidade. 
Os dados obtidos permitiram elaborar o gráfico 1, comparando as horas programadas, as horas efetivamente trabalhadas e as perdas por horas de máquinas paradas.

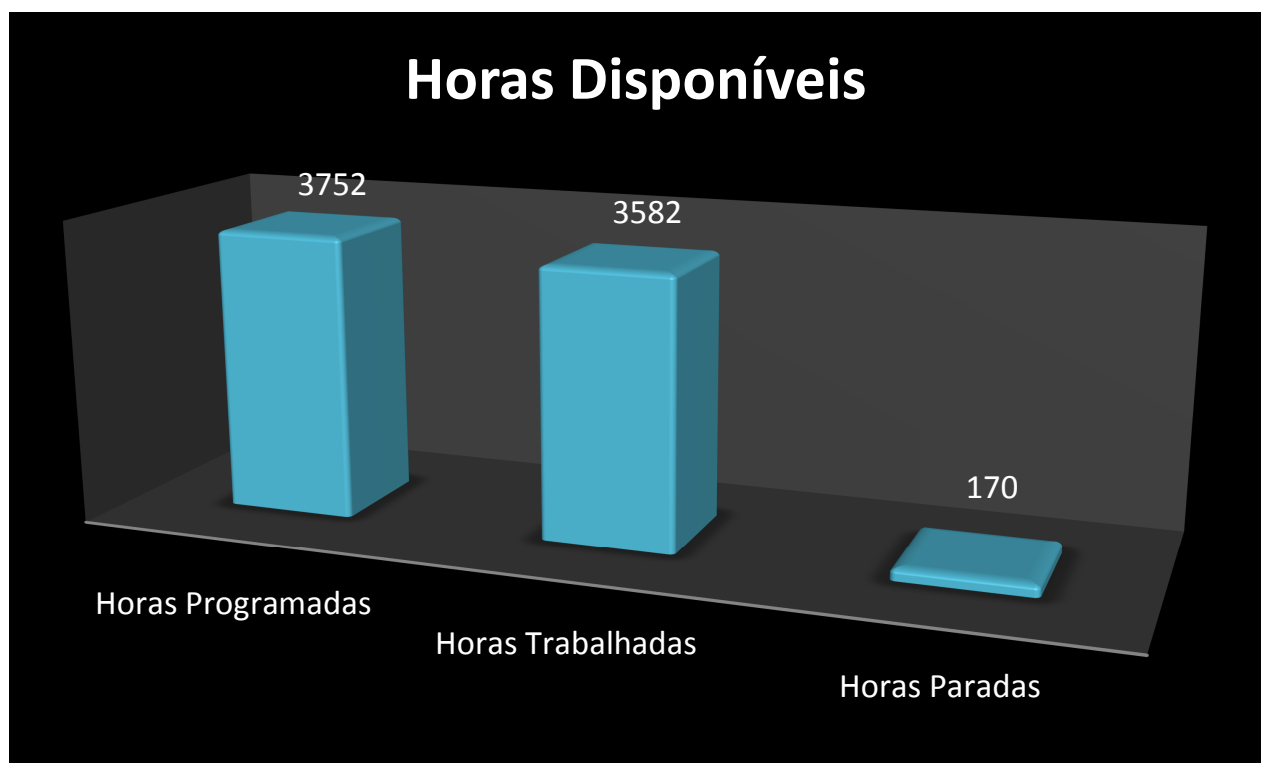

\section{Gráfico1 - Horas Disponíveis Atual}

Fonte: Os autores

Com os dados obtidos no Gráfico 1, efetuando-se a razão entre as horas efetivamente trabalhadas pelas horas programadas, obteve-se o resultado de $95,4690 \%$ de disponibilidade de máquinas, resultado superior àquele verificado antes da implementação da TPM, de 92,3746\%, revelando um avanço após a implementação da TPM.

A compilação dos dados obtidos nos formulários analisados permitiu a elaboração do gráfico 2, relacionando e comparando a quantidade total de produto produzido no período analisado, a quantidade de produto bom (produto em conformidade com a qualidade desejada) e as perdas por falta de qualidade.

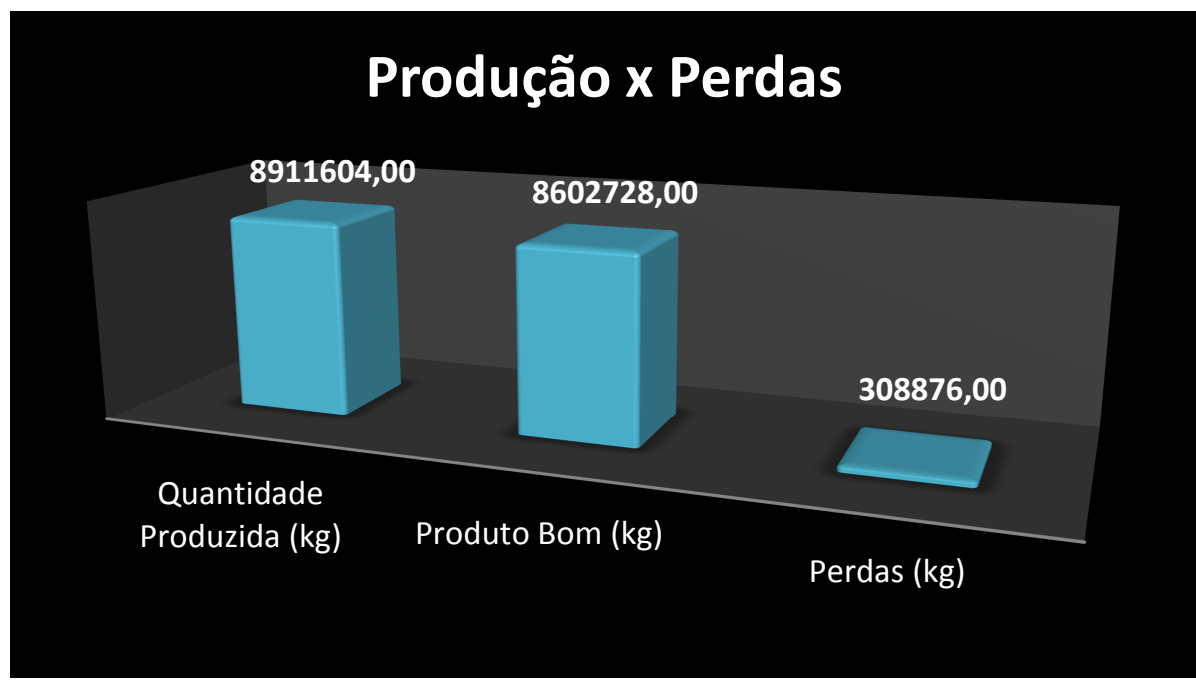

Gráfico 2 - relação entre Produção e Perdas

Fonte: Os autores 
Analisando-se o gráfico 2, pode-se efetuar o cálculo do desempenho da qualidade, mediante a relação percentual entre a quantidade de produto produzido em conformidade com os padrões de qualidade adotados e a quantidade total de produtos da linha de produção. O cálculo conduz ao resultado de 96,5340\%, índice também superior àquele verificado antes da implementação da TPM que era de 96,1118, assim, também nesse quesito, foram observados avanços após a ação implementada.

Multiplicando os valores dos três índices, obtidos após a implantação da TPM, disponibilidade de máquinas, desempenho da qualidade e desempenho da linha de produção, obtém-se o índice OEE que é a eficiência global do equipamento na linha de produção, no valor de $90,59 \%$, superior ao OEE anterior de $85,77 \%$. Dessa maneira, todos os indicadores de qualidade e de produtividade obtiveram melhorias após a implementação da TPM na linha de produção.

\section{CONCLUSÃO}

Mediante a condução desse trabalho foi possível constatar que com a implantação da TPM houve um aumento em todos os índices sendo que o mais significativo foi a disponibilidade do equipamento que aumentou 3,09\% enquanto o desempenho aumentou $1,67 \%$ e qualidade $0.42 \%$. Isto significa que a linha foi mais eficiente, com os mesmos recursos foi possível aumentar o volume de produção.

De acordo com os resultados obtidos, é possível concluir que a implantação da TPM traduziu-se em ganho para a empresa, pois permitiu aumentar a eficiência e a eficácia da linha de produção. Além de contribuir com o aumento do desempenho da qualidade, o aumento da disponibilidade do equipamento devido à menor ocorrência de paradas por falhas, possibilitou um aumento na produtividade de $122 \mathrm{~kg} /$ hora. Esse incremento possibilitaria um aumento de produção de 437 toneladas no período analisado.

Além desses benefícios primários, outros benefícios decorrem da implantação da TPM, como a menor depreciação dos equipamentos pela metodologia implementada, reduzindo os custos de produção.

Dessa maneira, o objetivo desse trabalho de analisar o indicador OEE antes da implantação da TPM e comparar esses dados com aqueles obtidos após a implantação da 
TPM para verificar se houve melhorias, permitiu comprovar no estudo de caso os avanços de produtividade e qualidade apontados pelo aprofundamento teórico realizado sobre o tema.

Esse trabalho contribui apresentando evidências dos avanços obtidos no estudo de caso realizado além de servir de orientação para outras empresas que buscam melhorar a produtividade e a qualidade dos processos produtivos.

\section{REFERÊNCIAS}

FERNANDES, A. R. Manutenção Produtiva Total: uma ferramenta eficaz na busca da perda-zero, 2005, 18p. Monografia (Especialização em Engenharia de Produção), Universidade Federal de Itajubá, 2005.

HANSEN, Robert C. Eficiência global dos equipamentos: uma poderosa ferramenta de produção/manutenção para o aumento dos lucros. Tradução Altair FlamarionKlippel. Porto Alegre: Bookman, 2006.

KARDEC, Alan; NASCIF, Júlio. Manutenção - função estratégica. 3. ed. Rio de Janeiro: Editora Qualitymark, 2009.

MELLO, Carlos Henrique Pereira; TURRIONI, João Batista. Metodologia da pesquisa em engenharia de produção: estratégias, métodos e técnicas para condução de pesquisas quantitativas e qualitativas. Apostila do curso de especialização em qualidade e produtividade. Universidade Federal de Itajubá: Itajubá, 2012. Disponível em:

<http://www.carlosmello.unifei.edu.br/Disciplinas/Mestrado/PCM-10/Apostila-

Mestrado/Apostila_Metodologia_Completa_2012.pdf>. Acesso em: 08 nov. 2015.

NAKAJIMA, Seiichi.Lamaintenance productive totale (TPM). Traduzido por Yoko

Sim, Christine Condominas e Alain Gómez. Paris, France: Afnor, 1989.

SANTOS, Ana Carolina Oliveira; SANTOS, Marcos José. Utilização do indicador de eficácia global de equipamentos (OEE) na gestão de melhoria contínua do sistema de manufatura - um estudo de caso. In: ENEGEP, 27, 2007, Foz do Iguaçu. Anais... .[Foz do Iguaçu]: ABREPO, [2007]. p. 1-10. Disponível em: <http://www.abepro.org.br/biblioteca/ENEGEP2007_TR570426_0265.pdf> Acesso em: 07 nov. 2015.

TENÓRIO, Fernando Guilherme. Flexibilização organizacional, mito ou realidade? Rio de Janeiro: Editora FGV, 2000.

XENOS, Harilaus Georgius d'Philippos. Gerenciando a manutenção produtiva: o caminho para eliminar falhas nos equipamentos e aumentar a produtividade. Nova Lima: INDG Tecnologia e Serviços Ltda., 2004.

YAMASHINA, H. - Challenge to World Class Manufacturing - International Journal of Quality\& Reliability Management, 17(2), pp. 132-143, 2000

YIN, R. K. Case study research: design and methods. Thousand Oaks: SAGE Publications, 2002.

YOSHICAZEM, Okano. Manutenção Produtiva Total. São Paulo: IMAN, 2002. 